\title{
MATEO LÓPEZ Y LA PLANTA DE LA IGLESIA MONÁSTICA DE SAN MARTÍN PINARIO DE SANTIAGO
}

\author{
SimÓN Vicente LÓPEZ \\ Doctor en Historia del Arte \\ simvicente@hotmail.com
}

Se profundiza en la lectura de la planta de la iglesia monástica San Martín Pinario de Santiago, atribuida al arquitecto portugués Mateo López, de acuerdo con las consignas de la Reforma Católica en torno a la Eucaristía.

Palabras clave: San Martín Pinario; Mateo López; Concilio de Trento; Sillería de coro; Liturgia; Felipe II.

\section{MATEO LÓPEZ AND THE PLAN OF THE MONASTIC CHURCH OF SAN MARTÍN PINARIO IN SANTIAGO}

An in depth study of the plan of the church of San Martín Pinario in Santiago de Compostela, attributed to the Portuguese architect Mateo López, according to the Catholic Reformation doctrines concerning the Eucharist.

Key words: San Martín Pinario; Mateo López; Council of Trent; choir stalls; liturgy; Felipe II.

En 1589, sin respuesta favorable del concejo de Santiago a la petición de solar público para acrecentar su templo, los monjes de Pinario decidieron construirlo en otra parte; acordaron sustituir el edificio medieval, quizá las celdas y claustros que habían usado hasta entonces. El cardenal Jerónimo del Hoyo, anonadado por la mole que asomaría a los pocos años, calificó la vieja iglesia como "buena y suficiente". No debía de serlo. Los benitos quisieron levantar una inmensa que condijese a las observancias de la Congregación de San Benito, a la que estaba adscrita la abadía ${ }^{1}$. Sospecho que lo estatuido en la sesión XIII del Concilio de Trento a propósito de la Eucaristía fue tenido en cuenta cuando se trazó el plan a seguir. Un plan que insumiría años de problemas derivados de la escasez de espacio, de la oposición del cabildo catedralicio, al que pertenecía el suspicaz Del Hoyo, y de unas trazas sujetas a la interpretación de sucesivos maestros. La necesidad de mantener los of icios impondría que la fábrica románica y la nueva coexistiesen hasta 1661. De ahí que la definitiva se asentase sobre un suelo irregular y se adaptase al caserío circundante encajándose en él mediante sucesivas expropiaciones. Asimismo, se dice que la falta de terreno provocó que se tergiversase la habitual orientación por la anticanónica W-E.

\footnotetext{
${ }^{1}$ A principios del XVI los monjes ya habían construido dos nuevos claustros -por el maestro Juan de Lemos en 1511-, y consolidado fábricas preexistentes - por el taller de Juan de Álava- y los cuartos de la enfermería -por Juan de Herrera, el de Gajano-. Véase Goy, 1995a: nota 3; 2005: 103. Añado a la lista ciertas obras de hacia el 1570. Se habla en la documentación del quarto nuebo y de toda la piedra necesaria para él, encargada por el mayordomo fray Gregorio de Torres al cantero Francisco González. Archivo de la Catedral de Santiago (en adelante A.C.S.), Protocolos notariales, P 054, fols. $141 \mathrm{r}-142 \mathrm{v}$.
} 


\section{Mateo López y el diseño universal del monasterio}

El artífice escogido fue el portugués Mateo López, perteneciente a una familia con prosapia en el oficio. Partícipes de algunas de las construcciones más reseñables de la arquitectura portuguesa del último tercio del XVI, los Lopes no restringieron su talento a las principales villas del norte de Portugal ${ }^{2}$. Se trasladaron al Reino de Galicia, donde prestaron sus servicios en casas de la Orden de San Benito, como las de Tenorio, Poio, Lérez y Celanova. Este trabajo previo en fábricas benitas ha sido subrayado para explicar su posterior fichaje por la comunidad de $\mathrm{Santiago}^{3}$. No tengo nada que objetar. Al contrario, añadiría que el arquitecto ya había trabajado para el cenobio años atrás, en cosas secundarias, y que entre 1585 y 1587 figuraba como maestro de obras ${ }^{4}$.

Esto último podría despejar la primera duda que nos asalta, concerniente al diseño originario, a la posibilidad de que López concibiese un proyecto universal del monasterio que incluiría, aparte la iglesia, desde el simple cillero, la bodega, la botica y así hasta la última celda, o se limitase a firmar la planta y los alzados del templo, a la espera del solar definitivo o del dinero para sufragar una empresa venidera ${ }^{5}$. Puesto que en el último tercio del quinientos ya se reconstruían los edificios más domésticos, cabe suponer que el convento sólo se habría planteado erigir ex novo el templo con el deseo impreciso de estrenar todo un complejo cuando las circunstancias lo permitiesen. Lo corrobora un dato aportado por Bonet Correa: en 1676, el cabildo, celoso del tamaño del monasterio, litigó para evitar el avance de la construcción hacia la Azabachería, adonde se abre una de las puertas más franqueadas de la basílica jacobea. Los monjes alegaron datos demostrativos que precisan el ínterin en que se habría pergeñado un proyecto más o menos decisivo: "el convento quiere proseguir las fabricas que tiene delineadas y empeçadas ha de 50 anos" y quiere acabar las partes ya empezadas "según la planta y montea que se hizo quando se delineo la obra" ". Se entiende que esa obra total se habría delineado durante el primer cuarto del XVII, lo que no desmiente que en 1589 la comunidad se hubiese planteado la erección de nuevos claustros y edificios.

Las obras comenzaron el 25 de julio de $1590^{7}$. Es curioso que a partir de ese año se firmasen acuerdos consecutivos con el arquitecto para dosificar la construcción, lo que significa que se manejó como el ejecutor episódico de sus propias trazas. El primer concierto se celebró siendo abad fray Antonio de Comontes y no se escrituró hasta el 28 de marzo de $1592^{8}$. Contrataron a Mateo López, maestro de canteria, vecino de la villa de Pontevedra, sobre el azer de la obra de la yglesia que en el dicho monesterio haze el dicho Mateo. Es la escritura de asiento del maestro para una obra que ya llevaba años dirigiendo, con un salario anual de cien ducados, asta que se acabe y el sea maestre de la dicha obra... y demas dello... le daran lo neçesario para su persona, criado y cavalgadura, ansi de comida, cama, posada dentro del monesterio. Otra de las condiciones le exigió que buscase un aparejador que supliese sus faltas, y es que sólo estaba obligado a visitar las

\footnotetext{
${ }^{2}$ Véanse Mato Reis, 1986: pp. 151-180. Ruao, 1996: pp. 146 y ss.

3 Véase Goy, 1996: 1-21.

${ }^{4}$ En 1587 testó el cantero portugués António Lopes, residente en Santiago como aparejador del maestro Mateu Lopez, cantero de la obra y fabrica del monesterio de San Martin. A.C.S. Protocolos notariales, P 101, fols. 93r-96v. El testamento revela que Mateo López, maestro de la obra, le adeudaba ciertas cantidades de reales en relación con su trabajo. Quizá ese António Lopes fuese miembro del clan de los Lopes (el de los Joao) al que pertenecía Mateo, vinculado a la ciudad de Porto y villas del norte de Portugal, como Guimaraes, Amarante y Viana do Castelo.

5 Vila, 1994: 450. Atribuyó al portugués la traza de todo el complejo.

${ }^{6}$ Bonet, 1966: 479.

7 Barreiro, 1965: 150.

${ }^{8}$ Es un contrato inédito. Hasta ahora se tenía uno del año 1593 como el primero.
} 
obras cuatro veces al año, de tres a tres meses ${ }^{9}$. Por tanto, su maestría fue intermitente. En otra cláusula, innegociable, se le pidió que diese la traça y moldes y todo lo nescesario que fuere menester para la dicha obra... y la seguira segun como esta enpeçada conforme a la planta ${ }^{10}$. Esto diluye toda incógnita relativa a posibles zozobras en torno al diseño original.

El mayordomo fray Lorenzo de Ávila firmó el segundo contrato el 12 de junio de 1593. Éste sí referido a la elevación de una primera capilla: una capilla de la yglesia que al presente se edefica, que es la primera capilla que esta pegada al cruzero a la mano hesquierda de la banda de las claustras... Siguieron otras advertencias sobre el tipo de cubrición. Son de relevancia para comprender lo más característico del abovedamiento de la iglesia, sus falsos casetones: .... se agan dentro de la dicha capilla veynte y çinco casas quadradas las quales seran llanas bien labradas y juntas y la casa del medio abera un floron conpuesto con sus serafines, mynsulas, follages... Esta primera capilla serviría de punto de partida para el resto del cuerpo del templo: $Y$ mas tiene de azer un arco tosco a pico, bien junto, para que sobre el se engrose la pared para sustentar las capillas que se an de azer en el cuerpo de la iglesia. Se sucedieron más advertencias. También son importantes; verifican que sí se había pensado en un plan universal (no en un diseño universal) en el que estaba prevista la construcción de algo más que la iglesia: $Y$ ara unos trabateles para la parte del altar de Nuestra Señora del Rosario que seran quatro trabateles, los dos que estan echos y los otros dos que de nuebo tiene de azer y asentarlos de manera que correspondan con las claustras que se an de azer para la dicha iglesia ${ }^{11}$.

\section{El retrocoro: la cabecera de la iglesia y su relación con otras fábricas coetáneas}

Otra de las incertidumbres que enturbia el papel jugado por Mateo López se refiere a la extraña disposición de la capilla mayor. La incertidumbre es doble: ¿se debe al portugués la estrambótica longitud del ábside o se trata de una injerencia posterior? Ese exceso ¿se concibió para albergar un retrocoro, a situar tras el altar, o la sillería que se tenía en mente iría colocada en el presbiterio, dejando el testero libre para acoger el típico retablo parietal?

Veamos. (Fig. 1) La iglesia del monasterio dibuja una planta de cruz latina inscrita en un rectángulo; de nave única, se resuelve en sus flancos con capillas-hornacina interconectadas. La principal, con su alargado ábside recto, se acompaña a cada lado por sendas estancias, relacionada la una con los usos propios de una sacristía y la otra con los de una statio o ámbito de paso ¿procesional? ${ }^{12}$

El determinismo que connota la invocación del Gesú y su epigonario de fórmulas espaciales encaminadas a señalar la relevancia del altar mayor aconsejó la indagación de otras referencias que podría haber adaptado el portugués. Atendiendo a la extravagancia del ábside, se buscaron modelos en la arquitectura portuguesa. Así, el origen del arquitecto sugirió la posible influencia del tipo instaurado supuestamente por Filippo Terzi en San Vicente de Fóra ${ }^{13}$ (fig. 2).

El análisis de otras plantas conventuales como la salmantina de San Esteban o la apelación al paradigma, Juan de Herrera y su catedral de Valladolid, sólo ratifica que la profundidad del ábside para cobijo de la sillería no era un arbitrio exótico, por lo menos en las décadas finales del XVI ${ }^{14}$.

\footnotetext{
${ }^{9}$ A.C.S. Protocolos notariales, P 109, fol. 692v.

${ }^{10}$ Todas las condiciones y el contrato en A.C.S. Protocolos notariales, P 109, fols. 691r-694r.

11 A.C.S. Protocolos notariales, P 116, fols. 281r-283v. Fue Pérez, 1930: 335, el primero referenciar este documento.

${ }^{12}$ Sigue sin discernírsele función concreta a esta estancia.

${ }^{13}$ Schubert, 1924: 268. Opinión que siguieron Bonet, 1966: 111. Goy, 1995a: 115-116. Véase también Kubler, 1959: 105 y ss.

${ }^{14}$ Esgrimidas por Vigo, 1996: 114-115.
}

Arch. esp. arte, LXXXIX, 353, ENERO-MARZO 2016, 85-94

ISSN: 0004-0428, eISSN: 1988-8511, doi: 10.3989/aearte.2016.07 


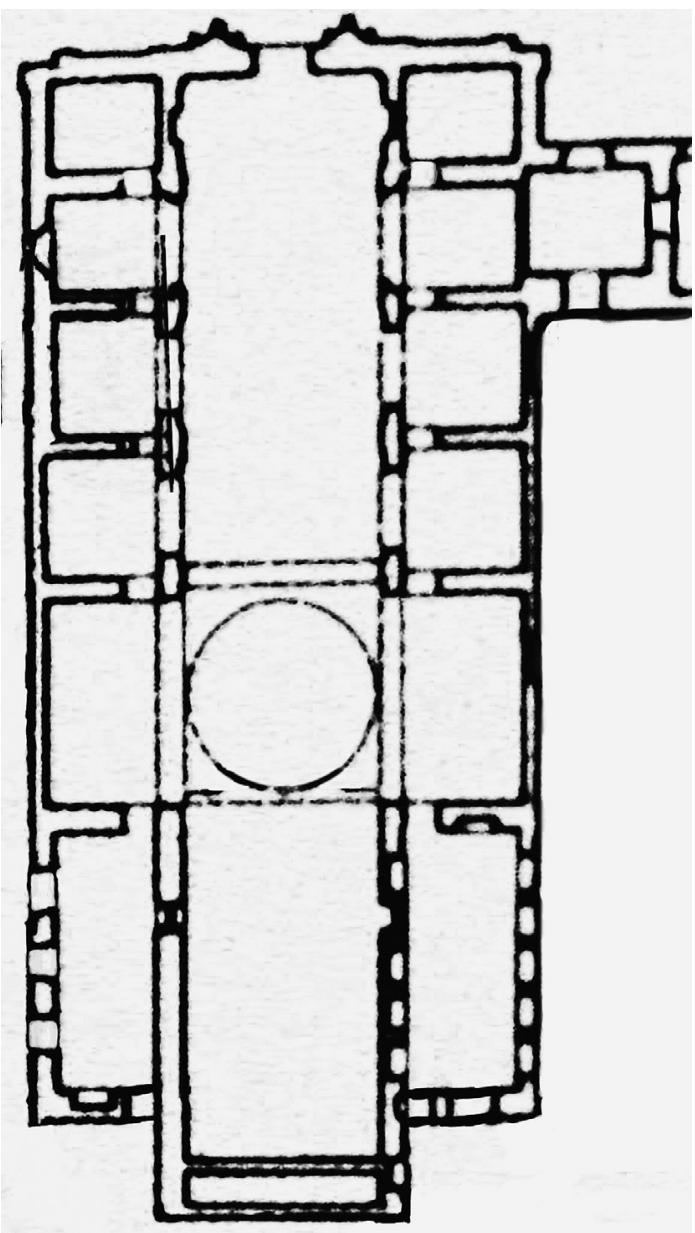

Fig. 1. Planta de la iglesia por Mateo López (1589). Propuesta hipotética.

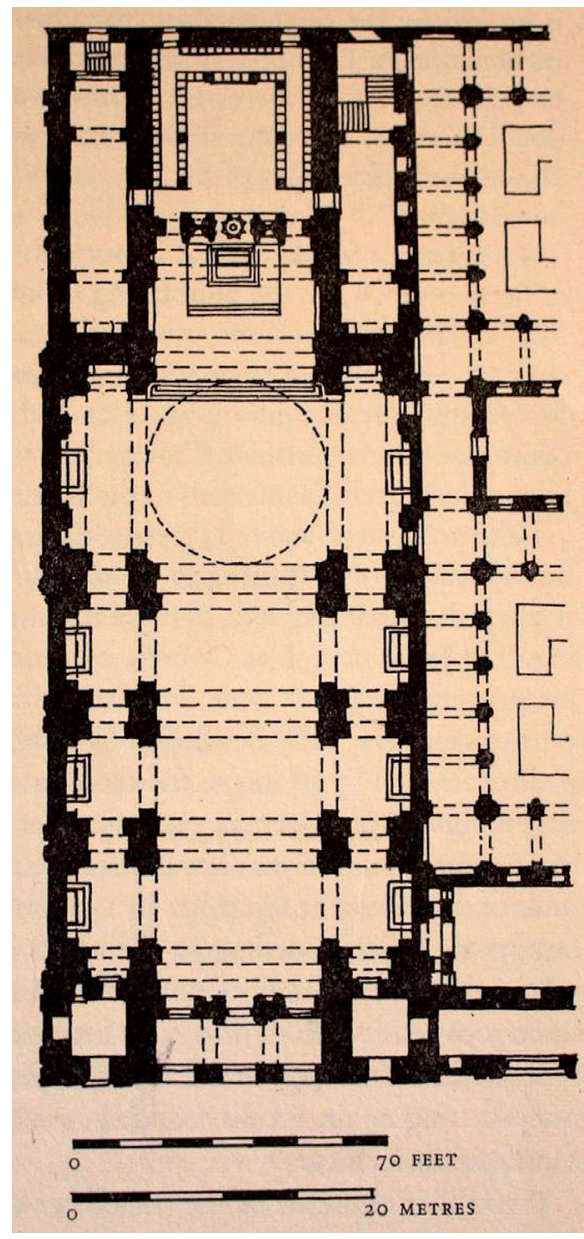

Fig. 2. ¿Juan de Herrera? Planta de la iglesia de San Vicente de Fóra de Lisboa. Fuente: G. Kubler, Art and architecture in Spain and Portugal and their american dominions: 1500 to 1800 , Penguin Books, 1959, p. 105.

En todo caso, podría tildarse de rareza a tenor del escaso número de iglesias españolas con esa organización. La cita de ciertos templos portugueses en los que notamos pautas similares -San Gonçalo de Amarante y Santo António de Montemor-, podría verificar la deuda del arquitecto con fórmulas "tradicionales" que habría conocido en persona ${ }^{15}$.

Más allá de la dificultad de explicar la transposición de esas y otras plantas en la obra santiaguesa, habría que empezar por pesquisar las razones en las querencias de los comitentes, no tanto en la trayectoria artística del arquitecto, patente en la ordenación del muro, el tipo de cubrición, el orden, la proporción o el ornato apetecidos.

${ }^{15}$ Vigo, 1993:342. 
Las diferencias a que aludí al comienzo, entre el ayuntamiento y el abad, quizá escondan el quid de una cabecera tan característica. Según el acta consistorial del 20 de agosto de 1585 entro frai Gaspar Baca, abad de San Martin, atento queria alargar su yglesia para mas hornato della, pedio a sus mercedes le dieran un calexon ${ }^{16}$. Ya sabemos que fray Gaspar no obtuvo sino la negativa del concejo, que los monjes se vieron abocados a rebuscar en su dominio el solar deseado y que fue este cambio lo que provocaría que de una sencilla ampliación se pasase a una construcción ex nihilo. Porque lo que querían era alargar su yglesia, lo que sólo se justifica por las medidas y el espacio de la medieval, que se habrían quedado obsoletos. Quiere decirse en términos puramente litúrgicos.

Repasemos éstos. La Congregación de Valladolid reguló un culto que reclamaba espacios amplios y funcionales, adecuados para el of icio de una liturgia protagonizada por la polifonía ${ }^{17}$. Una liturgia predispuesta a administrar la comunión con una frecuencia inusitada, según reivindicación de los monjes más conspicuos de la Orden que pasaron por San Martín, como fray Pedro Vicente Marcilla. En sus escritos concitó la comunión frecuente del laico: "Reciba con mayor frecuencia que las obligaciones de su estado le permiten, el santísimo Sacramento, y no sólo un día, u otro, sino aún cada día"18

El doble coro - que no la doble sillería- era ineludible atento la complejidad del ceremonial, adornado por la exclusividad de libros litúrgicos propios, como un missal consuetidunario diferenciado del breviario romano y particularmente rico. El antifonario y la consiguiente logomaquia de canto y órgano, se antojaban esenciales para mantener la concurrencia de un público ávido. Si en 1583 el capítulo general ordenaba que se abandonase el canto de órgano, el acta del capítulo celebrado a los dos años advirtió sobre los funestos resultados de asistencia alcanzados con un canto llano que debía de ahuyentar, de puro tedio, al auditorio profano: “...por aver dejado el canto de órgano, el qual en algunas partes estaba muy bien reçibido, se dejan de freqüentar nuestras yglesias y templos" ${ }^{\prime 19}$. Al cabo, la solemnidad del culto determinaría la entrada de novicios. El postulante sería valorado más por sus aptitudes vocales o su destreza ante el teclado que por el sempiterno desparpajo en latinidad: [...] Otrosi, atendiendo a la falta general que ay en toda la religion de organistas y cantores y a la particular en los colegios de ministros para el altar, mandamos al Padre Abbad no proponga a ningun junior para el colexio que no sepa lo sufficiente de tecla y canto para officiar ${ }^{20}$.

Retomando el ejemplo salmantino de San Esteban, se ha demostrado con documentos fehacientes que la cabecera de la iglesia se adelantó dos siglos a las instrucciones de un Ventura Rodríguez. El cambio del plan, con un profundo ábside donde acomodar los sitiales, se produjo por la intrusión de fray Martín de Santiago en el proyecto de Juan de Álava. Acaso porque estaba más familiarizado que éste con las salvedades de la misa conventual "dixo fray Martin que era menester que cupiese un coro de sillas en la dha. capilla mayor para uso del convento" ${ }^{21}$.

Otro de los ejemplos argüidos para explicar el ábside del portugués es el de los planos de fra Giovanni Vincenzo Casale para la iglesia de San Millán de Yuso, que amenazaba ruina ${ }^{22}$. Por mandato del rey, el italiano trazó en 1589 dos propuestas apenas diferentes en su concepción del espacio litúrgico, determinado por una cabecera con retrocoro ${ }^{23}$ (figs. 3 y 4).

${ }^{16}$ Archivo Histórico Universitario de Santiago. Fondo Municipal. Libro de actas del consistorio, fol. 744r. Cit. por Goy, 1996: 157. Algo similar pasó con la catedral vieja de Cádiz. Navascués, 1998: 73.

${ }^{17}$ Zaragoza, 2007: 229-232.

18 Tomo la cita de González, 2001: 359-378.

19 Zaragoza, 2007: 229.

${ }^{20}$ Archivo Histórico Diocesano de Santiago (en adelante A.H.D.S.), Fondo San Martín, Libro de Visitas, legajo 63, m. 79, fol. 97.

${ }^{21}$ Rodríguez, 1987: 29.

${ }^{22}$ Goy, 1995a: 117.

${ }^{23}$ Véanse Bustamante/Marías, 1991: 306-307. Moya, 2000: 73-96.

Arch. esp. arte, LXXXIX, 353, ENERO-MARZO 2016, 85-94

ISSN: 0004-0428, eISSN: 1988-8511, doi: 10.3989/aearte.2016.07 

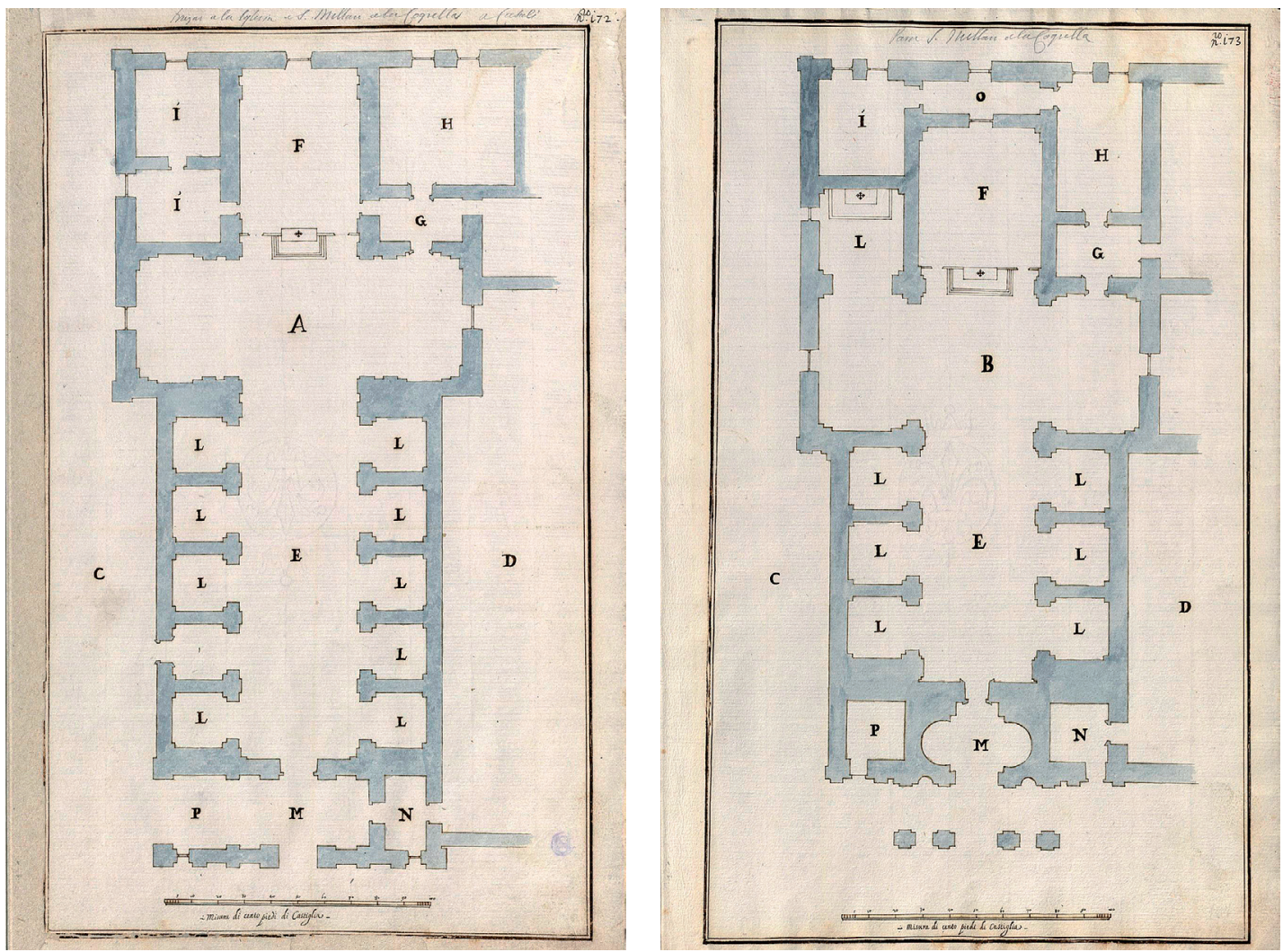

Figs. 3 y 4. Vincenzo Casale. San Millán de Yuso (1589). Iglesia apuntalada y dos propuestas de nueva planta. Biblioteca Nacional de España ( DIB 16/49/167; DIB 16/49/169 y DIB 16/49/170).

Siendo una solución pareja a la de San Martín Pinario, los diseños nos incumben por la intercesión de Felipe II, cuya implicación tal vez se vio azuzada por el señuelo de los siete infantes de Lara, sepultados en un convento caedizo. El rey, que encargaba por esos años el arreglo del monasterio agustino de San Vicente de Fóra a Herrera y a Terzi, también supervisó la evolución de las plantas del montañés para la catedral en que se había empecinado, la única que, sin ambages, podamos considerar contrarreformista ${ }^{24}$. Es sabido que en ellas se abogó por la receta del retrocoro $^{25}$ (fig. 5).

Es apabullante la coincidencia de fechas -1589/1590- de todas estas fábricas de modo que cobra atractivo la hipótesis de trabajo planteada por Navascués en torno a la probable tercería de Pellegrino Tibaldi en la decisión de Herrera de diseñar la catedral vallisoletana al modo italiano ${ }^{26}$. Es posible que Herrera, previo diálogo con el pintor, llevase directamente la secuencia coro-altarfieles de la seo de Milán a la de Valladolid y, escasos meses después, a Lisboa ${ }^{27}$. Abusando de la

\footnotetext{
${ }^{24}$ Rodríguez, 1992: 287-308.

25 Bustamante, 1983: 133 y ss.

${ }^{26}$ Navascués, 1998: 77.

27 Segurado, 1987: 99-112.
}

Arch. esp. arte, LXXXIX, 353, ENERO-MARZO 2016, 85-94 ISSN: 0004-0428, eISSN: 1988-8511, doi: 10.3989/aearte.2016.07 


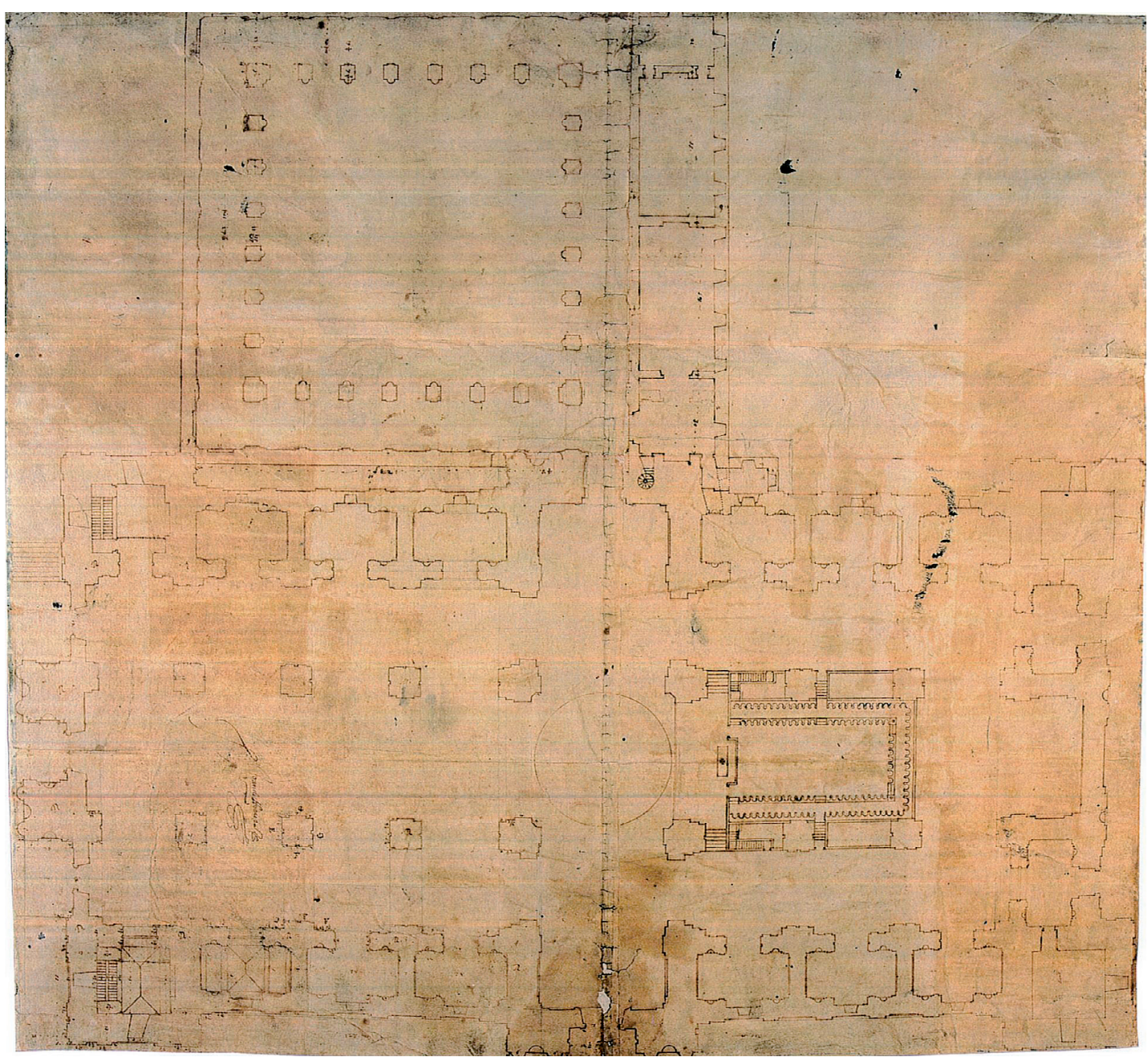

Fig. 5. Juan de Herrera. Planta de la catedral y claustro (¿1589?). Archivo General Diocesano de Valladolid (Planos y dibujos de la Catedral).

conjetura, me pregunto si no será admisible que la solución aportada por Tibaldi calase tanto en el arquitecto y en alguien tan sensible como Felipe II, hasta que acabase por propalarse fugazmente a través de otros proyectos, los de Yuso, Lisboa y Santiago.

Dado que el monasterio de San Martín llevaba a gala aquello de "El Real", con la nueva planta se garantizaba la riqueza del culto y, de paso, se lisonjeaba al rey asumiendo unas directrices espaciales homologadas, las mismas que había impuesto a sus nuevos súbditos portugueses, las que adoptó para su catedral, en fin, las que quiso propiciar enviando a un ingeniero real a Yuso para mayor dignidad del culto y de los personajes allí sepultados.

Arch. esp. arte, LXXXIX, 353, ENERO-MARZO 2016, 85-94

ISSN: 0004-0428, eISSN: 1988-8511, doi: 10.3989/aearte.2016.07 
El caso es que resulta más coherente que en el proyecto originario de Mateo López se dispusiese la sillería tras el altar ${ }^{28}$. Ésta haría juego con la posición del órgano en el testero, en virtud de unas constituciones puntillosas en cuanto a los usos del instrumento y de un ceremonial trasladado del observado en San Benito el Real ${ }^{29}$. Fuese o no por complacer al rey, los benitos quisieron modernizar su templo, repito, desde aquella petición al concejo. Por tanto, debería verse el cambio de iglesia como consecuencia de los desvelos por adaptarla a la concepción del espacio de acuerdo con lo acuñado en Trento y -sin resistirme al tópico- con lo refrendado más tarde por Borromeo, no precisamente en sus Instrucciones, sino en $s u$ duomo milanés con la actuación tutelada de Pellegrino Tibaldi ${ }^{30}$. Tómese como otra propuesta de trabajo.

\section{BIBLIOGRAFÍA}

Barreiro Fernández, Xosé Ramón (1965): "Abadologio del monasterio benedictino de San Martín Pinario en Santiago de Compostela (1607-1835)". En: Studia Monástica, vol. VII, 1, Abadía de Montserrat, pp. 147-188.

Bonet Correa, Antonio (1966): La arquitectura en Galicia durante el siglo XVII. Madrid: CSIC.

Bustamante García, Agustín (1983): La arquitectura clasicista del foco vallisoletano (1561-1640), Valladolid: Institución Cultural Simancas.

Bustamante, Agustín / Marías, Fernando (1991): “Álbum de Fra Giovanni Vincenzo Casale”. En: Dibujos de arquitectura y ornamentación de la Biblioteca Nacional. Siglos XVI y XVII, Madrid: Publicaciones COAM, pp. 306-307.

González Lopo, Domingo Luis (2001): "Las paradojas de la Contrarreforma: el debate sobre la comunión frecuente". En: Entre nós. Estudios de Arte, Xeografía e Historia en homenaxe ó profesor Xosé Manuel Pose Antelo, Santiago de Compostela, pp. 359-378.

Goy Diz, Ana (1994): "Mateo López y su interpretación de los modelos clasicistas". En: Los clasicismos en el Arte Español. X Congreso del CEHA, Madrid, pp. 314-326.

Goy Diz, Ana (1995a): "La Iglesia del Monasterio benedictino de San Martín Pinario". En: Monjes y Monasterios Españoles. Actas del Simposium (1/5-IX-1995) (coord. por Francisco Javier Campos y Fernández de Sevilla), San Lorenzo del Escorial, Servicio de publicaciones, T. I, pp. 101-133

Goy Diz, Ana (1995b): La arquitectura en Galicia en el paso del Renacimiento al Barroco (1600-1650). Santiago y su área de influencia, Santiago de Compostela.

Goy Diz, Ana (1996): "La influencia de la reforma benedictina en la renovación de las fábricas de los monasterios gallegos". En: Actas del Simposio Internacional A obra de arte total nos séculos XVII e XVIII, Braga, pp. 1-21.

${ }^{28}$ No concuerdo con Vigo, 1996: 112-113. Aduce que la planta de la iglesia se mantuvo incólume desde el diseño originario, no así la decisión de ubicar el coro al fondo de la capilla mayor, que relaciona con el papel jugado por Ginés Martínez, quizá pretendido por la comunidad a instancias del General de la Orden. Ginés pudo conocer "las ventajas de la solución retrocoral a través del proyecto realizado por Juan de Herrera para la catedral vallisoletana" o los diseños de Casale para Yuso. Opino que podrían haber conocido esos diseños antes de la llegada del jiennense quien, por cierto, se había visto implicado antes de su llegada a Santiago en el rechazo ex profeso de la solución retrocoral. Fue en la catedral de Cádiz, una de las pocas, si no la única, que tuvo originariamente su coro al modo romano. Navascués, 1998: 73 y nota 128 .

${ }^{29}$ Al catálogo de Zaragoza, 2005: 318-338, sumo el manuscrito 555 de la Biblioteca Xeral de la Universidade de Santiago. Si se lo lee con calma se verá que perteneció originalmente a San Benito el Real, pues se alude en él al fundador, Juan I.

${ }^{30}$ Véase Jobst, 2006: 91-126.

Arch. esp. arte, LXXXIX, 353, ENERO-MARZO 2016, 85-94 ISSN: 0004-0428, eISSN: 1988-8511, doi: 10.3989/aearte.2016.07 
Goy Diz, Ana (2005): "La arquitectura. De la reforma de los Reyes Católicos a la Desamortización. El resurgir de los monasterios en el Renacimiento". En: Opus monasticorum. Patrimonio, arte, historia y orden (José Manuel López Vázquez coord.), Xunta de Galicia, pp. 99-166.

Jobst, Cristoph (2006): "Liturgia e culto dell'eucaristia nel programma spaziale della chiesa. I tabernacoli eucaristici e la trasformazione dei presbiteri negli scritti ecclesiastici dell'epoca intorno al Concilio di Trento". En: Lo spazio e il culto. Relazioni tra edificio ecclesiale e uso liturgico dal XV al XVI secolo (a cura di Jörg Stabenow), Venezia: Marsilio, pp. 91-126.

Kubler, George (1959): Art and architecture in Spain and Portugal and their american dominions: 1500 to 1800. Harmondsworth: Penguin Books.

Mato Reis, António (1986): "Lopes-Uma família de artistas en Portugal e na Galiza". En: Revista de Guimaraes, vol. XCVI, Guimaraes, pp. 151-180.

Moya Valgañón, José Gabriel (2000): “La iglesia de San Millán de la Cogolla de Yuso”. En: Los monasterios de San Millán de la Cogolla: VI jornadas de arte y patrimonio regional: San Millán de la Cogolla, 6, 7 y 8 de noviembre de 1998, (Ignacio Gil-Díez Usandizaga coord.). La Rioja: Instituto de Estudios Riojanos, pp. 73-96.

Navascués Palacio, Pedro (1998): Teoría del coro en las catedrales españolas. Madrid: Real Academia de Bellas Artes de San Fernando.

Pérez Costanti, Pablo (1930): Diccionario de artistas que florecieron en Galicia durante los siglos XVI y XVII. Santiago de Compostela: Imprenta del Seminario Conciliar.

Rodríguez G. de Ceballos, Alfonso (1987): La iglesia y el convento de San Esteban de Salamanca. Estudio documentado de su construcción. Salamanca: Centro de Estudios Salmantinos.

Rodríguez G. de Ceballos, Alfonso (1991): "Liturgia y configuración del espacio en la arquitectura española y portuguesa a raíz del Concilio de Trento”. En: Anuario del Departamento de Historia y Teoría del Arte, vol. III, Madrid, pp. 43-52

Ruao, Carlos (1996): Arquitectura Manierista no noroeste de Portugal. O Italianismo e o Flamenguismo. Coimbra: Universidad de Coimbra.

Schubert, Otto (1924): Historia del barroco en España. Madrid: Saturnino Calleja.

Segurado, Jorge (1987): "Juan de Herrera em Portugal". En: As relaçoes artísticas entre Portugal e Espanha na época dos descobrimentos: II Simpósio Luso-Espanhol de História da Arte, Coimbra: Livraria Minerva, pp. 99-112

Vigo Trasancos, Alfredo (1993): "La iglesia monástica de San Martín Pinario en Santiago de Compostela. Proyecto, fábrica y artífices”. En: Compostellanum, vol. XXXVIII, números 3-4, Santiago, pp. 337-361.

Vigo Trasancos, Alfredo (1996): "El arquitecto jiennense Ginés Martínez de Aranda y la iglesia de San Martín Pinario en Santiago de Compostela”. En: Norba-Arte, Universidad de Extremadura: Servicio de Publicaciones, Tomo XVI, pp. 103-129,

Vila Jato, Ma Dolores (1994): "Precisiones sobre la construcción del monasterio de San Martín Pinario de Santiago". En: Tiempo y espacio en el arte. Homenaje al Profesor Antonio Bonet Correa, T. I, Madrid, pp. 449-459.

Zaragoza Pascual, Ernesto (2005): “Ceremonial benedictino vallisoletano”. En: Studium ovetense: Revista del Centro Superior de Estudios Teológicos del Seminario Metropolitano, nº 33-34, Oviedo, pp. 318338.

Zaragoza Pascual, Ernesto (2007): "La música litúrgica en el monasterio de Celanova (siglos XII-XIX)". En: Rudesindus. El legado del santo, (ed. a cargo de Francisco Singul), Xunta de Galicia, pp. 222-237.

Fecha de recepción: 17-VII-2014

Fecha de aceptación: 09-X-2014

Arch. esp. arte, LXXXIX, 353, ENERO-MARZO 2016, 85-94

ISSN: 0004-0428, eISSN: 1988-8511, doi: 10.3989/aearte.2016.07 